\title{
Maintaining good dental practice: the East Lancashire approach to dentists whose performance gives cause for concern
}

\author{
J. G. Whittle, ${ }^{1}$ and J. L. Haworth, ${ }^{2}$
}

\begin{abstract}
The Consultant in Dental Public Health and the Local Dental Committee in East Lancashire have developed a local system, similar to that being set up for general medical practitioners, to help general dental practitioners whose performance is causing concern. GDPs approved it at an open meeting of practitioners. A Dental Performance and Assessment Group has been set up and one problem has already been resolved to everyone's satisfaction. The model is recommended to dentists in other areas.
\end{abstract}

Collowing receipt of guidance from the

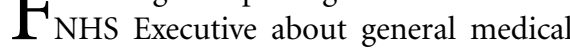
practitioners whose performance gave cause for concern, ${ }^{1}$ East Lancashire Health Authority approved the setting up of a local system based on a model devised by its Medical Adviser. The time, therefore, appeared opportune to develop a similar system for the dental profession. Because of difficulties in recruiting dentists to East Lancashire it is important that those whose performance is deteriorating are helped to overcome their problems before their ability to practise is threatened. The dental profession generally also needs to reassure the public that measures are in place to protect them from under-performing dentists. Although the General Dental Council was consulting on its proposed Performance Review Scheme at the same time, ${ }^{2}$ it was clear that, even when the scheme had been agreed, new legislation would be required. As a result nothing was likely to be implemented in the near future. The Consultant in Dental Public Health discussed the issues with local members of the profession who saw considerable merit in developing a local system, which would

\footnotetext{
${ }^{1}$ Consultant in Dental Public Health, ${ }^{2}$ Medical Adviser, East Lancashire Health Authority, 31/33 Kenyon Road, Lomeshaye Estate, Nelson, Lancashire BB9 5SZ

Correspondence to: Dr J. G. Whittle REFEREED PAPER

Received 25.10.99; accepted 26.01.00 (C) British Dental Journal 2000; 188: 539-542
}

\section{In brief}

- The dental profession in East Lancashire has taken the lead in developing this model.

- The model mirrors that used by the Local Medical Committee and this facilitated acceptance by the Health Authority.

- The Performance and Assessment Group is a sub-committee of the Local Dental Committee.

- Lay membership of the Group is important.

- Help and support can be offered to general dental practitioners at an early stage.

complement any national scheme to be agreed later. The Medical Adviser's paper was revised to adapt it to dental practice and sent formally to the Local Dental Committee (LDC) for consideration and comments.

The LDC was receptive to the idea and nominated a sub-group to meet with the Consultant so that the document could be discussed in detail. The sub-group agreed that there were advantages in using the medical model as a basis; East Lancashire Health Authority had approved it and if any training was arranged dentists could be included. This would minimise any extra resources needed. However, some changes were agreed to make the paper more relevant to general dental practitioners.
The revised paper (Appendix 1) was circulated to all general dental practitioners in East Lancashire. It was then discussed and agreed at the LDC's annual open meeting of dental practitioners. This was particularly heartening because a study in the north of England has identified professional loyalty as a potential problem in tackling underperforming doctors. ${ }^{3}$ Subsequently the Health Authority approved the system, the key features of which are:

- Owned by the Local Dental Committee

- Local Dental Committee and Health Authority working together

- Accepted by all the dental profession working in the GDS in East Lancashire

- Dental Performance and Assessment (PASS) Group set up to receive evidence and arrange to meet with practitioners as appropriate

- One of Health Authority's non-executive directors a lay member of the Group.

- Assessment process

- Mentoring support for poorly performing dental practitioners

- Review visit by assessment team

- Training issues for members of the Dental PASS Group and individual practitioners.

Two meetings of the East Lancashire Dental PASS Group have now taken place. Most of the discussion has been about refining the process of assessment but, nevertheless, some difficulties experienced by one dental practitioner have already been resolved to everyone's satisfaction.

The time appears propitious for other local dental committees and health authorities to collaborate in developing similar machinery.

1 NHS Executive. GPs whose performance gives cause for concern. FHSL(97)37. Leeds: NHS Executive, 1997.

2 General Dental Council. Performance review scheme for the dental profession. A consultation paper. London: General Dental Council, 1998.

3 Taylor G. Underperforming doctors: a postal survey of the Northern Deanery. Br Med J 1998; 316: 1705-1708. 


\section{Appendix 1 \\ Maintaining Good Dental Practice: \\ Dentists whose performance gives cause for concern}

\section{Introduction}

In November 1997, the NHS Executive issued Guidance on the Role of the NHS in the General Medical Council (GMC)'s Performance Procedures and the Rehabilitation of Doctors. The purpose of this guidance was primarily to protect patients from doctors whose performance is seriously deficient: that is, where a doctor's performance is consistently unsafe and potentially jeopardises the health and lives of patients. East Lancashire Health Authority is working with the local medical committee (LMC) to develop a local system which will identify such doctors (and practices) before a referral to the GMC becomes necessary, and to offer help and support to improve performance to a safe and satisfactory level.

From the dental professional perspective, it would be helpful if similar procedures were in place to give confidence to the general public and to maintain a system of internal control of standards within the local profession. It would also ensure that poorly performing dentists were treated sensitively and offered help to improve their performance.

This paper draws heavily on a report, about maintaining good medical practice, presented to East Lancashire Health Authority in August 1998 by the Director of Public Health and prepared by the Medical Adviser.

\section{The principles involved in a local}

decision

- Any system developed must be in partnership between the local profession represented by the East Lancashire Local Dental Committee (LDC) and the East Lancashire Health Authority.

- The system must be understood and accepted by all the profession for whom it is intended locally.

- The prime purpose must be supportive, with sensitivity for the needs of the general dental practitioner.

- The process must be transparent, fair and provide confidentiality for individuals.

- It must be accessible for self-referral.

- It must guard against prejudice arising from age, cultural differences, ethnicity or type of practice, by ensuring the involvement of all stakeholders.

\section{Defining under-performance}

Three themes arise when attempting a definition of under-performance. These are:

3.1 Performance that places patients 'at risk' ie safety of clinical practice.

3.2 Performance that fails to meet explicit required standards ie variation from accepted normal professional standards.

3.3 Performance that departs from what is considered normal practice ie variation from the practices of a normal general practitioner.

It is important to note that:

- Under-performance relates not only to clinical care but also to organisational and managerial skills in the delivery of health care.

- Under-performance covers the triad of knowledge, skills and attitudes.

- Under-performance is a pattern of performance, in a range of areas, over a period of time.

- Dentists may under-perform but the whole practice may also be dysfunctional.

- Under-performance can be viewed under the four elements of the commissioning accountability framework, namely:

- Clinical and professional

- Patients and the wider public

- Management

- Finance

- Consensus opinion would suggest that the most important criterion to apply is that of 'when patients are placed at serious risk of harm by any aspect of a dental service'.

\section{Identification of under-performance -} the process:

Dentists who under-perform will usually fall into one of three defined categories:

4.1 Those dentists who recognise that their performance is regularly below an accepted professional standard and who present themselves for remedial support, eg because of the level of complaints against them.

4.2 Those whose performance is so worrying that immediate action is obligatory.

4.3 The group with which this document is mainly concerned, those dentists identified as performing poorly but who, by early identification and appropriate intervention, may avoid referral to the General Dental Council (GDC). This group are likely to be identified either by the Health Authority, by the LDC network or by the Dental Practice Board.

\section{The local system - how it will work:}

There are five identifiable steps in the working of a local system and these are as follows:

Step 1. The Health Authority and/or the LDC, by using a wide range of information sources, become aware that a dentist, or a practice, may be under-performing. At this stage all that may be required is an informal visit by the Health Authority's General Dental Practice Adviser and/or LDC secretary. However, concerns may be sufficient that step 2 is required. The indicators used to reach this decision must be open, reliable, valid and predictive of poor or underperformance.

Step 2. The available information is reviewed by a sub-committee of the LDC known as the Dental Performance and Assessment Group or 'the Dental PASS group'. This group will be composed of the following members: 
- LDC Secretary

- One other full member of the LDC

- General Dental Practice Adviser

- Consultant in Dental Public Health

- Dental Tutor

- Lay person appointed by the Health Authority

Other ad-hoc members might be added as deemed appropriate. That the PASS group is 'under the umbrella' of the LDC should help to alleviate any fears that these procedures are a means of the Health Authority being seen to target general practitioners and will ensure that those entrusted with performance issues have a clear understanding of the nature of general practice.

If the sub-committee/PASS group believes that, on the evidence available, there is a case for investigating further, it will arrange for an assessment visit to the practice.

Step 3. The assessment visit to the practice would be made by two or three members of the PASS group and ideally this should include one representative from both the Health Authority and the LDC. Another person with particular expertise may be necessary to reflect the nature of the concern. The assessment group should be sensitive to the fact that the greater the number of visitors, the more intimidating it may be perceived. The GDP undergoing assessment must have the right of a friendly colleague (eg a local colleague or British Dental Association (BDA) or LDC representative but not a legal representative) being present during the visit.

The assessment would use a set proforma, as developed and agreed by the PASS group, if necessary over a number of visits. It is vital that the criteria used are open, valid and reliable.

Step 4. Poor or under-performance may be excluded by the assessment, in which case no further action is taken and the process stops at this point.

However, if the assessors confirm a problem of under-performance - and this may well require the deliberation of the whole PASS group - then a sequence of further steps are taken as follows:
- The dentist agrees to a remedial package of support and signs a contract with the PASS group to that effect. Other options may be retirement from the practice, or direct referral to the GDC if there is refusal of support by the practitioner.

- The dentist chooses a mentor from a list of suitably qualified and trained practitioners.

- The assessors report their findings to the PASS group who will agree to the proposed course of action.

- Those with the responsibility for the educational component of any intervention will draw up a detailed action plan.

- The action plan is discussed by the mentor with the GDP. The mentor will provide on-going support, motivation and review of progress during the course of the action plan.

Step 5. There will be a review visit(s) by the assessment team, as and when it is deemed appropriate. At this visit, the dentist will be asked to provide evidence to support change in the previously identified areas of under-performance.

\subsection{Performance indicators}

There are two occasions when indicators of under-performance are used within the above process. Firstly, when the initial identification of under-performance is made (probably, most frequently by the Health Authority) and secondly, during the practice visit as part of the assessment process. The former indicators are likely to be mainly factual information whereas the latter indicators reflect a method of diagnosis by firsthand examination and interview 'a structured diagnostic process'.

Any set of indicators will have to be sensitive enough in order to detect an under-performing dentist from within a group practice which may be masking such behaviour, but not so demanding that it reflects excellent practice only.

Some of the information used to make the initial identification of under-performance may be informal or 'soft information' such as 'word of mouth' from the $\mathrm{CHC}$, patients, carers, practice managers, dental nurses, other dental practitioners, hospital and community dental staff etc. It is important to ensure that such 'soft information' is only viewed within the wider perspective of more robust, qualitative indicators and should not be relied upon as a sole indicator of under-performance.

\section{Understanding the causes of under- performance}

The practice visit and assessment is not purely to diagnose under-performance, if present, but to also identify the underlying causes. Concerns relating to the health of the dentist may be a significant feature responsible for under-performance and may need to be addressed using the services of an identified, supportive Occupational Health Service and/or GDC Health Procedures and Sick Dentist Scheme.

Once the underlying causes for poor performance have been identified by the structured diagnostic process, appropriate support can be put in place. This may not be purely educational but has to be aimed at the root of the problem eg interpersonal relationships within the practice. Although an individual dentist may be identified as under-performing, it may be incumbent on several members of the practice team to be involved in the solution.

A list of possible causes of under-performance is given in the Appendix. This list is not intended to be exhaustive but merely illustrative.

\section{Interventions}

Interventions are most likely to be effective when the GDP recognises the need for change and is compliant with the steps necessary to create that change. Providing the climate for change and maintaining it will require a mentoring system and will also involve a clear contractual agreement between the GDP and the Dental PASS group.

There are three main types of interventions:

\subsection{Educational intervention}

It is important to make the point that any educational input should be entirely separate from the assessment process in order to protect the integrity of the system. An educational package may well involve input 
from members of the Regional Directorate of Post-Graduate Education especially in terms of resources and funding of identified educational needs.

Educational packages might include any of the following: PGEA courses; personal learning plans; practice-based multi-disciplinary learning; CAL programmes; peer review; audit group work; strategic planning facilitation; and management training

\subsection{Organisational intervention}

Including measures to improve the practice infra-structure including staff, premises, practice management support, staff training etc.

\subsection{Health intervention}

If health problems are identified as a concern, these will need to be addressed outwith these defined performance procedures.

\section{Mentoring}

Mentoring would be involved with all three aspects of intervention. The mentor:

- Clarifies and refines the educational package for the GDP.

- Helps and encourages the GDP through the plan including the development of personal learning plans.

- Acts as a link to the educationalists locally.

- Helps the GDP to reflect on learning and to audit change.

- Prepares the GDP for the re-assessment visit(s).

- May provide a separate report to the Dental PASS group for a subsequent visit.

Clearly, there are resource implications including the need to train members of the

\section{Possible causes of under- performance by GDPs: \\ - Professional isolation \\ - Lack of continuing professional education \\ - Physical health problems \\ - Mental health problems \\ - Drug \& alcohol problems \\ - Stress-related problems \\ - Low morale \\ - Complaints \\ - Poor practice infrastructure \\ - Workload problems \\ - Interpersonal relationship problems \\ - Tragic and upsetting professional experiences \\ - Unexplained idiosyncratic behaviour}

Dental PASS group on assessment skills and the mentors in attaining and developing relevant skills. The mentee will also have to appreciate, and have documented in the contract, that there may be a need for a mentor's report as part of the ongoing review of performance. A more serious breech of the mentor-mentee relationship would occur if the mentor felt that it was essential to report serious deficiencies which were perceived as putting patients at 'grave risk', and which were previously unknown. Such a step is mandatory to provide essential safeguards but would not be taken without reference to senior educationalists within the North West Region and also to the East Lancashire Dental PASS group.

\section{Resource issues}

The East Lancashire Health Authority and relevant Post-Graduate Departments will have to consider ways of supporting local schemes and remedial packages, as well as those dentists who, having been referred directly to the General Dental Council, subsequently require local support.

Decisions will have to be made regarding the contribution of the 'poorly performing general dental practitioner' towards the overall educational package and training costs. It may not be appropriate for the Post-Graduate Education Allowance (PGEA) to be used entirely for this purpose and the GDP would normally be expected to make some financial contribution to the delivery of the identified educational package.

Additional considerations will have to be related to the payment of locum fees during a re-training period and the level of reimbursement for peripatetic staff posts.

\section{Re-assessment}

Objectives must be clearly set out and agreed at the beginning of the process. It would be desirable for the same assessors to re-visit the practitioner on any future reassessment of progress towards the agreed objectives. Difficult decisions will be surrounding the timing of discharge of the practitioner from the arrangements or whether there is a need for the provision of long-term support.

If no progress has been made following re-assessment, the Dental PASS group will need to consider other future options including GDC referral or voluntary retirement of the individual general practitioner. 